\title{
JOHANN A. P. GESNER ON APHASIA*
}

by

\section{ARTHUR L. BENTON}

OUR present knowledge of aphasic disorders is the product of an evolution which spans millennia. Delineation of these conditions, their differentiation from other types of disorder of speech and language, and ideas about their causation and basic nature developed very gradually. The earliest medical writings (including the Hippocratic Corpus) made reference only to a general 'speechlessness' or 'loss of voice' which seemingly covered all types of impairment of speech and language, including not only those which today would be called aphasic but also those due to frank paralysis and to disturbed states of consciousness, as well as those of psychogenic origin.

The beginnings of a differentiation between aphasic and non-aphasic disorders of speech can be found in the writings of some post-Hippocratic authors. Thus Caelius Aurelianus distinguished between impairment of speech due to paralysis of the tongue and 'cases of loss of speech resulting from some other disease'. According to Creutz, the same distinction was made by most medical writers of the late classical period. One can also point to the reference to a case of traumatic alexia by Valerius Maximus (c. A.D. 30), and to Galen's assertion that 'word memory' could be lost as a consequence of head injury, as further indications that distinctions between various types of speech and language disorder were being made. By this time also the decisive role of abnormalities of the brain or its ventricles in causing some types of speech disorder was clearly recognized.

Renaissance medicine witnessed further developments. First, the distinction between speech impairment due to 'paralysis of the tongue' and an amnesic type of speech disorder was clearly drawn. Secondly, an initial speculative step in the topical localization of language function was taken by Antonio Guainerio when he advanced the conception that certain types of aphasia were due to a loss of memory caused by excessive accumulation of fluid in the posterior ventricle. Finally, the concept of the cerebral origin of aphasic (or anarthric) disabilities became a practical medical reality when physicians and surgeons, such as Nicolo Massa and Francisco Arceo, inferred from the observation of aphasia following head injury that fragments of the skull might have become lodged in the brain and interfered with its functions. Acting on this inference, they searched for and removed the fragments from the brain, this intervention being followed by restoration of speech in the patients.

Two quite important contributions to knowledge of aphasia appeared in the seventeenth century. In 1676 , the Danzig physician Johann Schmidt published the first reasonably clear description of alexia and paraphasia. A few years later,

\footnotetext{
* From the Neurosensory Center and the Departments of Neurology and Psychology, University of Iowa, and supported by Grants B-616 and B-3544 from the National Institute of Neurological Diseases and Blindness. Neurosensory Center Publication No. 39.
} 


\section{Fohann A. P. Gesner on Aphasia}

Peter Rommel described a patient with severe expressive aphasia who nevertheless showed preserved capacity for serial speech (an observation which was made again some sixty years later by Olof Dalin). A few further observations on aphasia were made during the first half of the eighteenth century, the most notable perhaps being Van Swieten's brief description of anomia and Linnés account of a patient with paraphasic disturbances.

All these contributions were extremely brief, even though some of them, such as those of Schmidt and Rommel, were remarkably informative in spite of their brevity. Many details, which we would consider today to be of decisive importance, were not mentioned; moreover, all the reports were of an essentially descriptive nature, little attention being paid to the mechanisms underlying the observed clinical phenomena. However, in 1770 there appeared what it is fair to describe as the first major work devoted to the subject of aphasia. This was a chapter by Johann Augustin Philipp Gesner (1738-1801) entitled 'Die Sprachamnesie' in the second volume of his Samlung von Beobachtungen aus der Arzneigelahrheit und Naturkunde. The chapter, which covers 73 octavo pages, is about 7,000 words in length.

Gesner was a prolific medical writer whose interests were quite broad. In addition to his original writing, he translated Latin and French treatises into German and was actively engaged in editorial work. His five-volume Samlung, published over a span of eight years, was perhaps his major work. He also wrote a series of four 'recent advances' volumes entitled Die Entdeckungen der Neuesten Zeit in der Arzneygelahrheit ( $1777-88$ ) which covered contemporary developments in all branches of medicine.

\section{Die Sprachamnesie}

The first paragraph of Die Sprachamnesie reads as follows:

I relate the history of a disease which appears worthy of attention not only because it is certainly uncommon but also because it belongs among those documents in the literature on the human mind which are instructive to psychologists and because I am able to report the opinions and prescriptions of some famous and distinguished physicians who were consulted about it.

There follows the history as it was written by the patient's own physician in a letter dated 6 February 1769 . Herr K.D. was a seventy-three-year-old man who had seldom been ill and had always enjoyed the fruits of a regular life. His only complaint during recent years had been bouts of catarrh which would last some weeks and were accompanied by the production of an extraordinarily viscous material. In December of the previous year he had once again begun to suffer from catarrh. In the beginning of January he experienced a cramp in the muscles of the mouth and at the same time an itching sensation like the crawling of ants. The cramp was relieved by taking some pinches of cherry brandy. Unexpectedly, on 26 January, he showed a quite distinctive impairment in speech, together with some mental confusion. He spoke fluently but used 'extremely unusual and self-made words that nobody could understand'. The speech impairment had persisted unchanged until the date of the letter from the patient's physician. The mental confusion appeared to have increased. 
There was no evidence of paralysis in any part of his body. 'These are the main features of a disease which I at least have never encountered in my thirty years of practice.'

There follow eight letters which were written by four consulting physicians between 6 February and 16 July 1769 and which include observations, interpretations of the underlying pathology and a variety of prescriptions. The observations indicate that the patient could neither write nor read. One of the consultants (W. A - r), the author of three of these eight letters, concludes that 'the incapacity to make himself understood by us through words or other signs is neither in the tongue nor in other members, for the tongue is skilful enough to produce three times as many words as are necessary. I cannot explain this in other than these terms: nothing is wrong in this patient except the higher mental performances.' This consultant also pointed out that, if the cause of the difficulty were in the tongue, the patient would not be incapable of writing, as he obviously was.

Gesner's opinion was first sought about a year after the onset of the patient's illness. There is no evidence to indicate that he actually saw the patient. However, having reviewed the observations and opinions of earlier consultants, he also 'wanted to know about those phenomena which pertain to the more speculative part of medicine. I therefore requested the answers to some questions, which will be mentioned presently. These answers were provided not by a physician but by a man who personally observed the patient daily and whose eyes had been opened by worldly wisdom.' The report of this observer reads in part as follows:

The words which Herr K.D. pronounces are for the most part meaningless sounds. However, their total number is not very great, in that a meaningless word is often repeated successively and only occasionally replaced by others which are equally incomprehensible. These sounds sometimes disappear completely and one does not hear them any more; instead, new coinages appear which last a longer or shorter time. For example, the sound 'began', without fixed meaning, which occurred constantly at the beginning of the illness is no longer uttered a halfyear later. Instead, one hears a newly created word, 'Zettejuset' or 'Zettennoset', countless times during the course of a day. Numerals, such as $40,50,60,70,80,90$, which he uses to serve him in the course of speech, are also to be added to this category.

Doubtlessly these sounds are not always associated with the same ideas for him. They express, or at least are intended to express, all those ideas which he wishes to communicate with others. Their total number is scarcely 100. Thus his currently favourite word 'Zettejuset' can mean more than 1000 things. It is also used by him indiscriminately and mixed up with other words in such a manner that his speech is incomprehensible.

At the same time there also occur occasional meaningful words which for the most part concern only familiar things and are not always within the power of the speaker. Examples are such expressions as 'obedient servant', 'most humble servant', 'good morning', 'I do not wish to', and several other similar expressions which had always characteristically been used by this man of choleric temperament, as well as swear words such as, 'Oh God; Oh God' and 'Damn Foolishness', whereby he indicates his futile efforts.

For the most part he uses these words in their proper meaning. However, I have also observed that if I drink to his health and he wants to thank me, the word, 'Adieu', is brought forth instead of the usual formula. He is likely to say 'Good evening' in the morning and 'Good morning' in the evening involuntarily. Thus in a quite special sense he seems to have lost complete control of his tongue. 


\section{Johann A. P. Gesner on Aphasia}

Writing and speaking are equally defective. He cannot write his full name even once. When he tries to write something else (which he seldom does because he is aware of his incapacity) he produces words on paper which are as incomprehensible as those he utters.

Nor can he read. These signs of ideas make no impression on him although other more concrete objects arouse the appropriate concepts in him. It is just this circumstance about which the patient, who always found great pleasure in reading, often complains.

Objects, when they are of an external sensory nature, certainly arouse the correspondingly correct ideas in him. The patient recognizes everyone whom he knew before, asks about the circumstances of people with whom he has associated, makes observations about them in accordance with their status, age, sex, etc., and, as has always been characteristic of him, praises, finds fault, or laughs at them (and with justification).

I cannot actually maintain that I have personally observed a loss of certain concepts in him unless such a loss may be inferred from the fact that he does not like to have excerpts from books presenting general spiritual or moral truths read to him. Nor does he pay any attention to them, which seems to show that many abstract concepts may have been lost and can be aroused only with difficulty, if at all, by the external signs which we call words. Otherwise he understands the speech of those around him completely and often to their admiration, unless it is presented in too diffuse a manner or, as mentioned above, concerns abstract matters. Moreover, he can also make his own ideas recognized through external signs and demonstrations to such a degree that, if one guesses the meaning of the signs, they represent quite correct and coherent ideas.

The patient is also aware that he speaks unintelligently and, when he repeats some of these words, has often laughed and joked about it.

Now after a year his condition is essentially as has been described. However, it can be said that, physically and mentally, he has improved rather than got worse. His mental powers have also become stronger, his ideas being more orderly and more definite. A few comprehensible words have also appeared. In brief, after one has observed and spoken with the patient at some length, nothing seems to be wrong with him except his speech. I do not know that I can better make his condition more intelligible and understandable except by saying that if a person who is not acquainted with the German language and who did not know that the patient was sick should observe him and hear him talk, he would take him for a healthy, ordinary man who is speaking an unfamiliar language.

In his discussion, Gesner first emphasizes that 'just as some mental powers become weakened without injury to others, memory also can be specifically impaired to a greater or lesser degree with respect to only certain classes of ideas'. Some reports from the literature as well as a personally observed case are cited to illustrate this point.

The first brief case report describes aphasia and alexia in a lawyer following a 'sleep' of nine days duration. In due time, he was able to read some words, being more successful in Latin than in German. He would write whole paragraphs in both Latin and German in an elegant hand, but they made no sense nor could he read them. He would often start a conversation, speaking understandably and clearly, and then falter in the middle of it.

A second case report describes a patient, an abbot, who was aphasic and alexic but who retained the capacity to recite familiar prayers. He partially regained his ability to read, the degree of recovery being greater for Latin than for German. The patient himself felt that he had suffered some decline in judgement, in the ability to calculate and even in understanding the speech of others.

A third case report describes a patient who could not speak, read or write but who could understand the speech of others. A fourth and a fifth describe patients who could read silently with understanding but who could not read aloud.

Gesner then points out that memory constitutes voluntary control over ideation or imagination (Phantasie). 'Speaking and writing are functions of memory 


\section{Arthur L. Benton}

while reading and hearing are functions of ideation.' The patient suffered essentially from a disturbance of memory which, however, primarily involved language. His poor grasp of the 'external signs' of abstract ideas was not due to an impairment in ideation but rather to a weakness of attention which is common enough in old age. This difficulty in appreciating symbolized abstract ideas was apparent only when a whole series of them was presented; the meaning of a single abstract idea presented in isolation was adequately understood. Thus while he was unable to read whole passages, he could identify specific days on the calendar. Moreover, he seemed to be able to read the Bible. Gesner concedes that it is difficult to prove that the patient did indeed read with understanding but he believes this to be likely.

The patient's paraphasic speech is explained as follows:

The liveliness of an idea and the desire to communicate it quickly to another person often causes us to use inappropriate words, especially when our attention is concentrated on the idea. However, nobody maintains because of this that our ideation or our reason is disturbed. Therefore, I see only a forgetting of speech when Herr K.D. says meaningful words which do not correspond to his ideas or when he utters meaningless sounds that perhaps suggest to us a remote and often incomprehensible similarity to the correct words or give us a false impression of his thought.

Gesner's conceptualization of the anatomic and physiologic correlates of 'speech amnesia' is rather vague and at times difficult to follow. Nevertheless, his basic ideas seem reasonably clear. He points out that an actual object or stimulus (even a heard or seen word) has a stronger effect on the mind than does memory. It is therefore understandable why the ability to recognize an object or word could be retained when other performances such as speaking or writing the name of an object, which depend upon memory, are lost. Recognition is subserved by the functioning of the sensory nerves and is essentially a receptive process. Hence it will be impaired only when there is actual injury of the mass of sensory nerves. In contrast, memory can be impaired even in the absence of such injury. The basis for loss of memory can be sought in another type of disease of the brain in which there is a weakness or inertia in the relationship between the different parts of that organ.

I look for the seat of this amnesia for speech in the interior of the organs, less in their organization as determined by the senses, than in the physical relationships of their parts, and particularly in a sluggishness in these relationships which arises out of dryness or rigidity.

He finds it unlikely that the patient's language disorder should be determined by injury of specific nerve fibres.

In our case I do not suspect pressure or obstruction of certain vessels because amnesia is practically the only symptom ... only language is lost. The vessels of the brain are surely not arranged in accordance with categories of physical ideas and therefore it is incomprehensible that these categories should correspond to areas of destruction. The words which have been lost to memory still serve in thinking. The fibre for the idea of a certain word would have to be completely inactive. But it is inactive only for voluntary performances. Moreover, the most common words are still remembered. How could pressure have made this choice?

The chapter concludes with a discussion of the uncertain prognosis in cases of this type and a survey of possible modes of treatment. 


\section{COMMENT}

There can be little doubt that this chapter by Gesner on 'speech amnesia' was indeed a major contribution and that, from a number of points of view, it represents a landmark in the study of aphasia. The first case report in it was incomparably more comprehensive and detailed than anything that had been published previously. It is a superb description of jargon aphasia and its value was recognized by later writers, such as Alexander Crichton and Jules Falret, who cited it in their discussions of disorders of speech and memory. Taken together, this case report and the five additional briefer ones presented in the discussion provide a wealth of information about such diverse clinical features of aphasia as jargon agraphia, differential impairment in reading one language as compared to another, retention of the ability to recite familiar prayers within the setting of grossly defective spontaneous, conversational and imitative speech, and inability to read aloud with at least partial preservation of the ability to read silently with understanding. There is even a suggestion of the existence of a sensory form of aphasia in Gesner's discussion of the first patient's inability to grasp the import of a series of abstract ideas and in his report of the testimony of another patient that the latter experienced difficulty in understanding the speech of other people.

I have mentioned that Gesner's discussion of the physiopathology and psychopathology of aphasia is at times obscure, particularly to a reader without a thorough grasp of the philosophic background of eighteenth-century German medicine. However, the tenor of his thought is clear enough. The jargon speech of his patient does not reflect dementia but rather a type of forgetting. Ideation and memory for words must be distinguished from each other. Ideation is evoked by the perception of physical objects and the action of the sensory nerves. The evocation of words follows ideation, and further neural energy or action is required for it to take place. Hence it is understandable that disease of the brain could impair verbal memory but leave ideation intact, i.e. that a patient might not be able to produce the name of an object but yet be able to recognize the object and know its significance. The material basis for such an impairment in verbal memory is a sluggishness or inactivity (Trägheit) in the relationships among the parts of the brain.

I do not think that one reads too much into Gesner's discussion when one sees it as an early statement of an associationist theory of aphasia, i.e. that the disorder consists of a failure to associate the appropriate vocal or graphic linguistic sign (word) with the intended image or idea. Like his predecessors, he spoke of a 'forgetting' of words but he went a step further by ascribing this form of amnesia to impairment in what today we would call 'associative processes'. Some twenty-five years later, Alexander Crichton stated the idea with greater clarity when he wrote that this 'very singular defect of memory ... ought rather to be considered as a defect of that principle, by which ideas, and their proper expressions, are associated, than of memory'.

Gesner does not seem to have made any further original observations on aphasia. After the publication of the Samlung, most of his energy was absorbed 


\section{Arthur L. Benton}

in the writing of his comprehensive reviews of current developments in the various branches of medicine which appeared over the period of $1777-88$. Summaries of his case of jargon aphasia and of another personally observed case (the last case in the chapter on Die Sprachamnesie) are included in the first volume of this series, but no other work having clear and specific reference to aphasic disorders, either by himself or others, is cited in any of the four volumes.

\section{REFERENCES}

I. Benton, A. L., and Joynt, R. J., Early descriptions of aphasia, Arch. Neurol., 1960, 3, 205-22.

2. - Three pioneers in the study of aphasia, 7. Hist. Med., 1963, 18, 381-4.

3. GRIGH ton, A., An Inquiry into the Origin and Nature of Mental Derangement, London, T. Cadell, Jr., and W. Davies, 1798.

4. Greutz, W., Die Neurologie des I-7. Jahrhunderts nach Chr., Leipzig, Georg Thieme, 1934.

5. Falret, J., Des troubles du langage et la mémoire des mots dans les affections cérébrales, Arch. gén. Méd., 1864, 3, 336-54, 591-6o9.

6. GeSner, J. A. P., Samlung von Beobachtungen aus der Arzneygelahrheit und Naturkunde, Nördlingen, C. G. Beck, $1769-76,5$ vols.

7. - Die Entdeckungen der neuesten Zeit in der Arzneigelahrheit, Nördlingen, Karl Gottlieb Becker, 1777-88, 4 vols.

8. MAJOR, R. H., A History of Medicine, Springfield, Ill., C. C. Thomas, 1954, 2 vols. 